\title{
Designing a Professional Development Course Sequence to Address Standard 4 Elements Using a CPD Framework
}

Jennifer Phillips, PharmD; Nancy Fjortoft, PhD; Karen Nagel-Edwards, PhD; Ana Quinones-Boex, PhD

Midwestern University Chicago College of Pharmacy

\begin{abstract}
ACPE defines personal and professional development as an expected outcome of the Doctor of Pharmacy degree program, but there is scarce data in the literature discussing methods for systematically addressing these concepts in curricula. This paper describes the development and attributes of a four-year professional development course sequence within a college of pharmacy designed to develop students' knowledge, skills, abilities, behaviors, and attitudes necessary to demonstrate self-awareness, leadership, innovation and entrepreneurship, and professionalism through their life-long career. Each course has at least one required activity addressing each of the four elements of Standard 4. The continuous professional development framework is used as a backbone to the course sequence structure, utilizing the four elements of CPD-reflect, plan, act, evaluate.
\end{abstract}

Keywords: professional development, leadership, professionalism, self-awareness, innovation, entrepreneurship

\section{INTRODUCTION}

Personal and professional growth are key elements in the success of any individual professional - from teachers and attorneys to physicians and pharmacists. Recently, the Accreditation Council for Pharmacy Education (ACPE) released new educational Standards for colleges of pharmacy that define personal and professional development as an expected outcome of the Doctor of Pharmacy degree program, thereby institutionalizing this concept. ${ }^{1}$ Specifically, ACPE Standard 4 lists four key elements to personal and professional growth: self-awareness; leadership; innovation and entrepreneurship; and professionalism. ${ }^{1}$ These personal and professional skills are considered essential to bridging scientific knowledge with optimal patient care and professional success.

There is some literature describing methods that various colleges of pharmacy have used to implement individual components of Standard 4. For example, one college of pharmacy offers an elective course to develop leadership skills and self-awareness, ${ }^{2}$ and other programs offer workshops ${ }^{3}$ and project-based activities ${ }^{4}$ to teach entrepreneurial skills. Methods to measure ${ }^{5}$ and promote ${ }^{6}$ professionalism within the pharmacy curriculum have also been described. A call to action was made encouraging colleges to share innovative ways of meeting this Standard. ${ }^{7}$ However, more information is needed on how institutions are systematically addressing all the components of Standard 4 within the curriculum.

This paper describes the development and attributes of a fouryear professional development course sequence at Midwestern University Chicago College of Pharmacy, a private,

Corresponding Author: Jennifer Phillips, PharmD Midwestern University Chicago College of Pharmacy $55531^{\text {st }}$ Street, Downers Grove, IL 60515

Email: jphillips@midwestern.edu four-year Doctor of Pharmacy program located in a Chicago suburb with an average class size of about 200 students. The course sequence was designed with the goal of developing students' knowledge, skills, abilities, behaviors, and attitudes necessary to meet the Standard 4 requirements and apply them throughout their life-long career.

\section{COURSE DESIGN FRAMEWORK}

The professional development course sequence is centered around the continuing professional development (CPD) framework, ${ }^{8}$ which involves the tenets of reflect, plan, act, and evaluate. The choice to focus on CPD was based on the team's belief that it is key to students' self-awareness, which is the foundation for development in the other domains of Standard 4 and will prepare students for lifelong learning. Below, we describe each stage of course design and implementation using the same CPD framework.

\section{Step 1: Reflect on the Design Elements}

When the 2016 ACPE Standards were released, a working team of faculty were identified by the Dean and the Chair of the Curriculum Committee to incorporate the elements of Standard 4 into the curriculum. This team was comprised of individuals who had developed and taught required or elective courses that addressed the elements mentioned in Standard 4, or had a keen interest in the topic. The team's first step was to reflect on current practices. From 2010-2019, the college curriculum included a required four-year course sequence called Reflective Portfolio I-IV, ${ }^{9}$ which was designed to meet the 2007 Accreditation Standards requiring colleges of pharmacy to document student self-assessment of achieving curricular outcomes. This course sequence utilized a series of lectures and faculty-advisor led workshops to introduce the students to the curricular outcomes and to teach them to meaningfully reflect and self-assess their knowledge and progress in achieving the outcomes. Students then documented their reflections and self-assessments in a web-based program. 
A quality improvement process was used successfully throughout the evolution of this course sequence.

The team ultimately decided to replace the reflective portfolio course sequence with a professional development course sequence. Since the reflective portfolio course sequence was successful in many areas, the team agreed to maintain some of those elements in the new professional development course sequence including: having a required course in every year of the curriculum, use of a pass/fail grading system, and use of an electronic platform for documentation and grading. Faculty advisor involvement was key to the success of the reflective portfolio course sequence because it decentralized the grading process among many faculty and provided a mechanism to foster the development of the student/advisor relationship. Therefore, involvement of faculty advisors was continued in the new course sequence.

The course sequence approach was specifically chosen because the team believed a focused, longitudinal course sequence using the CPD model would enhance the personal and professional development of all students by continual exposure and reinforcement. Students also learn about Standard 4 domains purposefully in other courses through discussions, by faculty role-modeling, and through student organizations' activities. Most of these formal and informal teaching activities were continued alongside the Professional Development course sequence.

\section{Step 2: Plan the New Sequence}

The team met regularly over the course of several months. First, the team reviewed all required and elective courses within the curriculum to collect teaching objectives, activities, and assessments that pertained to Standard 4, in order to centralize those learning experiences into one course sequence. The next steps were to search the literature, consult with a broad range of colleagues, and brainstorm additional objectives, activities, and assessments that could help the students achieve competence in all elements of Standard 4.

\section{Course Sequence Structure}

The course sequence was entitled Professional Development IIV. Utilizing the learning from reflection and background work, goals for the course sequence were developed and categorized under the four main phases of the CPD model. The goals were the same for each course within the sequence. For the "reflection" phase, goals focused on enhancing awareness of professional growth and development as well as personal strengths, weaknesses, attitudes, motivation, and biases. Under the "plan" phase, goals included defining individual personal and professional goals, writing appropriate SMART objectives for those goals, and planning which elective activities could aid in the accomplishment of those goals. For the "act" phase, goals centered on students' participating in required and elective activities. Finally, for the "evaluate" phase, goals involved using evidence and data to evaluate achievements and/or identify new step(s) for achieving goals and objectives.

Each course in the sequence is assigned 1 credit hour and a grade is reported on the transcript at the end of the longitudinal experience (i.e., the year). The required learning activities are strategically placed throughout the course sequence, taking into account other developmental activities and courses that are occurring in the curriculum. For example, interviewing skills was planned for the PS3 year to prepare students for professional interviews, which occur in the fourth professional year.

The course consists of both required and elective activities, which are mapped to Standard 4 elements (Table 1). The team determined that each course should have at least one required activity that addressed each of the four elements of Standard 4. Depending on the course, activities take place in one or multiple quarters. Many of the required learning activities include guided reflections and/or guided worksheets and students record and reflect on these activities within an electronic portfolio, which is reviewed by their faculty advisor.

For the elective activities, a menu was created by the faculty team (Table 2) taking into consideration already existing opportunities available at the college and logistical feasibility. These activities are not meant to be entirely prescriptive and the course director may approve additional activities at their discretion, if they feel that the activity allows for sufficient exposure to one of the Standard 4 elements. For each elective activity, students are required to complete a guided reflection on their experience. Many of the elective experiences are cocurricular and provided a mechanism for students to document their learning from these activities.

\section{Platform}

The faculty team considered various electronic platforms to house student portfolios that would be easily available to faculty mentors. We consulted with specialists in Information Technology and agreed that our course management software (Canvas ${ }^{\circledR}$, Salt Lake City, UT) could accommodate our needs.

\section{Required Reading}

There is one required textbook used consistently throughout the course sequence - The New Science of Learning, ${ }^{10}$ which is a book designed to teach higher education students metacognitive skills. It describes the biochemical processes involved in learning and memory and offers insights on how sleep, breaks, and exercise can be used to enhance learning and retention. The information within the book is reviewed in detail during the first course of the sequence and students are required to complete guided reflections on various aspects of the book. Concepts are subsequently reinforced in other courses within the sequence. 


\section{Assessment and Grading}

The course sequence is designed as a pass/fail course. Points are allocated for each required and elective activity and students must earn at least $70 \%$ of the total available course points to pass each course in the sequence. To help minimize workload on faculty advisors, students do not get detailed feedback on every assignment. For some assignments, students receive full credit just for having completed the activity. For these, the course director and/or teaching assistant review the submission and ensure that it meets the required level of "completeness." Each course in the sequence has about 6-10 assignments that are graded for completeness and 3-4 that are graded in more detail by the faculty advisor. The students are aware in advance which activities will be graded for completeness and which will be graded by the faculty advisor.

Faculty advisors grade the guided reflections using a standardized rubric embedded into the University's course management software. The rubric includes elements addressing content and professional quality and uses a 3category Likert scale of "exceeds expectations", "meets expectations", or "does not meet expectations."

Grading rubrics and reflection templates were developed with the intention that they would be used in all four courses and for every type of activity that requires a reflection. This process assists students in learning to consistently and thoroughly reflect and helps the graders consistently apply the rubric. The reflection templates consist of 5 questions that ask the student to describe the activity itself, their role in the activity, what they learned about themselves and others during the activity and how this activity contributed to their goals for the year.

\section{Step 3: Act}

Once the team completed the course design and courses were approved by faculty, the College successfully implemented Professional Development I in 2016-17 and Professional Development II in 2017-18. Faculty advisors were educated on their role in the course through emails and discussions at faculty meetings.

\section{Step 4: Evaluate}

Evaluation is on-going and is comprised of multiple methods. Minor changes were made to Professional Development I after its first offering based on student feedback. For example, the reflection worksheet was edited to included students' selfassessment of which Standard 4 elements characterize the activity best. In addition, more details were provided to guide students in the development of their resume.

To date, the college has had a $100 \%$ pass rate for this course sequence. In addition, student satisfaction has been assessed through utilization of the University's faculty and course evaluation system. Students in both cohorts (fall 2017 and fall
2018 ) indicated an overall satisfaction rating of the PD I course of 3.89 and 3.53 on a 4.00 scale. Individual student growth and development in each of Standard 4 domains over the course of the doctor of pharmacy program is also being monitored. This is an ongoing initiative involving surveying students at various time points in the course sequence to evaluate if self-assessed competency within Domain 4 elements improves over time.

Faculty input was sought on a more informal basis. Faculty reported overall ease in grading course assessments and enjoyed the required student/advisor meetings as a way of getting to know their students. Some minor changes were made based on faculty input. For example, more resume templates were provided to students to guide them in writing their resumes based on faculty input.

\section{DISCUSSION}

While there is much published data on individual elements of Standard 4 being incorporated into curricula, this course integrates all elements of Standard 4 into one course sequence utilizing the CPD framework. The value of this course sequence was to place these individual attributes within the framework of CPD and therefore use a systematic method for professional development. By using this framework, students could learn to value the CPD cycle in managing their own life-long professional development. In addition, the course sequence contains both required and elective activities. Students thereby can selfassess their needs, plan, act and evaluate. In other words, they can apply the CPD model when selecting an elective activity. This, coupled with guided reflections and the integration of cocurricular experiences, helps to create individualized learning experiences that foster achievement of each student's goals and objectives.

Finding an optimal method to assess growth and development for all of the Standard 4 elements over the course of several years remains a challenge. Self-assessment, in particular, may be a difficult skill to monitor change. In order to truly help our students in their personal and professional growth, pharmacy education needs to better understand options for measuring and assessing change in all of these dimensions.

\section{CONCLUSION}

The development and implementation of a Professional Development four-course sequence is described using the continuous professional development model. Educators can consider this approach when designing and implementing curriculum components centered around Standard 4. The limited outcome data that is available at this point indicates that students appreciate the course and have achieved stated course outcomes as demonstrated by the pass rate.
Acknowledgements: None
Funding/Support: None
Conflicts of Interest: None 


\section{REFERENCES}

1. Accreditation Council for Pharmacy Education.

Accreditation Standards and Key Elements for the Professional Program in Pharmacy Leading to the Doctor of Pharmacy Degree, 2016.

https://www.acpeaccredit.org/pdf/Standards2016FINAL.pdf. Accessed 2 Jun 2019.

2. Sorensen TD, Traynor AP, Janke KK. A pharmacy course on leadership and leading change. Am J Pharm Educ. 2009;73(2):Article 23.

3. Laverty G, Hanna L, Haughey S, et al. Developing entrepreneurial skills in pharmacy students. $\mathrm{Am} \mathrm{J}$ Pharm Educ. 2015;79(7):Article 106. doi: 10.5688/ajpe797106.

4. Shahiwala A. Entrepreneurship skills development through project-based activity in bachelor of pharmacy program. Curr Pharm Teach Learn. 2017(9):698-706. doi: 10.1016/j.cptl.2017.03.017

5. Chisholm MA, Ciobb H, Duke L, et al. Development of an instrument to measure professionalism. Am J Pharm Educ. 2006;70(4): Article 85.

6. Poirier TI, Gupchup GV. Assessment of pharmacy student professionalism across a curriculum. Am J Pharm Educ. 2010;74(4): Article 62.

7. Fjortoft $\mathrm{N}$. The challenges of the accreditation council for pharmacy education's standard four: identifying, teaching, and measuring. Am J Pharm Educ. 2016;80(5):Article 73. doi: 10.5688/ajpe80573.

8. Rouse MJ. Continuing professional development in pharmacy. Am J Health-Syst Pharm. 2004;61:206976.

9. Komperda KE, Phillips JA, Quinones-Boex AC, Borchert JS. Implementing and refining a reflective portfolio course sequence in a college of pharmacy. Curr Pharm Teach Learn. 2016; 8(6):855-862. Doi: 10.1016/j.cptl.2016.08.017

10. Doyle T, Zakrajsek T. The New Science of Learning: How to Learn in Harmony with Your Brain. Sterling, VA: Stylus Publishing; 2033. 
Table 1. Professional Development Classroom/Required Activities

\begin{tabular}{|c|c|c|c|c|}
\hline \multirow[t]{2}{*}{ Required Activity } & \multicolumn{4}{|c|}{ CAPE Domain 4 Aspect } \\
\hline & SA & $\mathbf{L}$ & IE & $\mathbf{P}$ \\
\hline \multicolumn{5}{|l|}{ Professional Development I } \\
\hline Defining CPD & & \multirow{9}{*}{$\sqrt{ }$} & \multirow{9}{*}{$\begin{array}{l}\mathrm{V} \\
\mathrm{v}\end{array}$} & $\sqrt{ }$ \\
\hline StrengthsFinder Exercise & $\mathrm{V}$ & & & \\
\hline New Science of Learning & $\mathrm{V}$ & & & \\
\hline Setting Goals/Creating SMART objectives & $\sqrt{ }$ & & & $\sqrt{ }$ \\
\hline APhA Career Pathways & $\sqrt{ }$ & & & $\sqrt{ }$ \\
\hline Careers in Pharmacy Panel & $\mathrm{V}$ & & & $\sqrt{ }$ \\
\hline Student Organization Panel & & & & \\
\hline What it Means to be a Professional & & & & $\sqrt{ }$ \\
\hline Professionalism Panel & & & & $\sqrt{ }$ \\
\hline \multicolumn{5}{|l|}{ Professional Development II } \\
\hline Evaluating Goals \& Setting Goals for PS2 Year & $\mathrm{V}$ & & \multirow{11}{*}{$\sqrt{ }$} & \\
\hline New Science of Learning Revisited & $\mathrm{V}$ & & & \\
\hline StrengthsFinder 2: Teams and Domains & $\mathrm{V}$ & & & \\
\hline Entrepreneurship Panel & & & & \\
\hline Career Resources and Leadership Panel & $\mathrm{V}$ & $\mathrm{V}$ & & $\sqrt{ }$ \\
\hline Networking & & & & $\sqrt{ }$ \\
\hline Public Health: The Opioid Crisis & & & & $\sqrt{ }$ \\
\hline Ethical Dilemmas & $\mathrm{V}$ & $\sqrt{ }$ & & $\sqrt{ }$ \\
\hline Ethical Behavior Realized & $\sqrt{ }$ & & & $\sqrt{ }$ \\
\hline Required Community Service & $\mathrm{V}$ & & & $\sqrt{ }$ \\
\hline Required Attendance at Pharmacy Professional Meeting & $\mathrm{V}$ & $\mathrm{V}$ & & $\sqrt{ }$ \\
\hline \multicolumn{5}{|l|}{ Professional Development III } \\
\hline Evaluation of Goals \& Setting Goals for PS3 Year & $\mathrm{V}$ & & \multirow{11}{*}{$\sqrt{ }$} & \\
\hline New Science of Learning Revisited & $\mathrm{V}$ & & & \\
\hline Leadership Skills & & $\sqrt{ }$ & & \\
\hline Innovations in Health Care & & & & \\
\hline Business Etiquette & & & & $\sqrt{ }$ \\
\hline Resume and Interviewing Skills & & $\mathrm{V}$ & & $\sqrt{ }$ \\
\hline Emotional Intelligence & $\sqrt{ }$ & & & \\
\hline Time Management and Life & $\mathrm{V}$ & & & $\sqrt{ }$ \\
\hline Cultural Competence & $\mathrm{V}$ & & & $\sqrt{ }$ \\
\hline Presentation Skills & & & & $\sqrt{ }$ \\
\hline Successful Careers Revisited & $\mathrm{V}$ & & & $\sqrt{ }$ \\
\hline \multicolumn{5}{|l|}{ Professional Development IV } \\
\hline Evaluation of Goals \& Setting Goals for PS4 Year & $\mathrm{V}$ & & & \\
\hline Financial Planning & & & & $\sqrt{ }$ \\
\hline Leadership Revisited & & $\sqrt{ }$ & & \\
\hline Career Panel Revisited & $\mathrm{V}$ & & $\sqrt{ }$ & $\sqrt{ }$ \\
\hline Creating New Clinical Services Panel & & & $\sqrt{ }$ & \\
\hline Interviewing Part 2 & & & & $\sqrt{ }$ \\
\hline Providing and Receiving Feedback & $\sqrt{ }$ & $\sqrt{ }$ & & $\sqrt{ }$ \\
\hline PCOA Exam & $\sqrt{ }$ & & & \\
\hline Top 300 Exam & $\sqrt{ }$ & & & \\
\hline Planning for the future: CPD Revisited & $\mathrm{V}$ & & & $\sqrt{ }$ \\
\hline
\end{tabular}

$S A=$ Self-Awareness; $L=L$ Leadership; $I E=I n n o v a t i o n$ and entrepreneurship; $P=$ professionalism; $\mathrm{APhA}=$ American Pharmaceutical Association; $\mathrm{CPD}=$ Continuing Professional Development 
Table 2: PD Elective Activities

\begin{tabular}{|c|c|c|c|c|}
\hline \multirow[t]{2}{*}{ Elective Activity } & \multicolumn{4}{|c|}{ CAPE Doman 4 Aspect } \\
\hline & SA & $\mathbf{L}$ & IE & $\mathbf{P}$ \\
\hline Read well-being book and complete a self-assessment & $\mathrm{V}$ & & & \\
\hline Watch a TED Talk; summarize and effect & $\sqrt{ }$ & $\mathrm{V}$ & $\sqrt{ }$ & $\sqrt{ }$ \\
\hline Student organization committee member - describe, summarize, and reflect & & $\sqrt{ }$ & & \\
\hline Community service activity - describe, summarize, and reflect & & & & $\sqrt{ }$ \\
\hline CCP Student Ambassador program - describe, summarize, and reflect & & $\sqrt{ }$ & & \\
\hline Attend State Legislative Day - describe, summarize, and reflect & & $\sqrt{ }$ & & $\sqrt{ }$ \\
\hline Attend Common-hour* event - describe, summarize, and reflect & $\sqrt{ }$ & $\sqrt{ }$ & $\sqrt{ }$ & $\mathrm{V}$ \\
\hline Read a selected leadership book - summarize, and reflect & & $\sqrt{ }$ & & \\
\hline Mentor a $1^{\text {st }}$ year student - describe, summarize, and reflect & & $\sqrt{ }$ & & \\
\hline Leadership role in a student organization - describe, summarize, and reflect & & $\sqrt{ }$ & & \\
\hline Group presentation to local school or community group regarding substance abuse & & & & $\sqrt{ }$ \\
\hline Participate in a prescription take-back event - describe, summarize, and reflect & & & & $\sqrt{ }$ \\
\hline
\end{tabular}

*Common hour is a professional seminar/presentation sponsored by on-campus organizations during time periods when no class is scheduled.

$\mathrm{SA}=$ Self-Awareness; $\mathrm{L}=$ Leadership; $\mathrm{IE}=$ Innovation and entrepreneurship; $\mathrm{P}=$ professionalism 